\title{
The Landscape of Checkpoint Inhibition in the Management of Hematological Malignancies
}

\author{
Shukaib Arslan ${ }^{1,2,{ }^{*}, \text { Alex Herrera }}{ }^{1}$, Monzr Al Malki ${ }^{1,2}$ \\ ${ }^{1}$ Department of Hematology and Hematopoietic Cell Transplantation, City of Hope National Medical Center, Duarte, the Unites States \\ ${ }^{2}$ Gehr Family Center for Leukemia Research, City of Hope National Medical Center, Duarte, the United States
}

\author{
Email address: \\ sarslan@coh.org (S. Arslan) \\ ${ }^{*}$ Corresponding author
}

\section{To cite this article:}

Shukaib Arslan, Alex Herrera, Monzr Al Malki. The Landscape of Checkpoint Inhibition in the Management of Hematological Malignancies. Cancer Research Journal. Vol. 9, No. 2, 2021, pp. 122-130. doi: 10.11648/j.crj.20210902.16

Received: May 25, 2021; Accepted: June 8, 2021; Published: June 30, 2021

\begin{abstract}
The programmed-death 1 (PD-1) and cytotoxic T-lymphocyte associated protein 4 (CTLA-4) pathways are inhibitory immune checkpoints involved in the escape of cancer cells from the immune system. Inhibition of these immune checkpoints can lead to the induction of body's immune response to these cancer cells. To activate the immune system against the tumor cells, various monoclonal antibodies targeting these pathways have been developed. Many of such antibodies have been approved for therapy in solid tumor malignancies and now some hematological malignancies. Here, we review the available data regarding the response to PD-1 and CTLA-4 pathway blockade in hematological malignancies including Hodgin lymphoma, non-Hodgkin lymhoma, multiple myeloma and myeloid neoplasms as well as before and after hematopoietic cell transplantation. We also discuss the specific concerns and differences related to their use in hematological malignancies (HMs) as compared to solid tumors.
\end{abstract}

Keywords: Immunotherapy, Checkpoint Inhibition, CPI, PD-1, PD-L1, CTLA-4, Hematological Malignancies

\section{Introduction}

Cancer therapy has been revolutionized by the discovery of the interplay between cancer cells and the host immune system. This involves regulatory immune checkpoints and the ability of tumor cells to evade and suppress immune attack by pathways including but not limited to programmeddeath 1 (PD-1) and cytotoxic T-lymphocyte associated protein 4 (CTLA-4) [1]. Monoclonal antibodies targeting these immune checkpoint receptors, or their ligands have shown promising results in the treatment of malignancies such as melanoma, non-small cell lung cancer, head and neck cancers, and urothelial carcinoma upon consequent approval by the FDA. These checkpoint inhibitors (CPI) are being increasingly studied in the setting of different lymphoid and myeloid malignancies.

Engagement of T-cell receptors (TCR) with antigen-human leukocyte antigen (HLA) complex and binding of T-cell costimulatory receptors with their respective ligands on the surface of antigen-presenting (APC) or tumor cells sets off multiple signaling pathways leading to T-cells inhibition or activation. CD28 and CTLA-4 are cell surface markers on the T-cells competing to bind to their ligands, CD80 (B7.1) and CD 86 (B7.2), respectively. Activation of CTLA-4 causes an inhibitory effect by stimulation of regulatory T-cells (Tregs) and inhibition of helper T-cells (Th) [2]. Interaction of PD-1, another $\mathrm{T}$ cell surface marker, with its ligands PD-L1 and PD-L2 has similar effects [3]. Under normal circumstances, these interactions help contain the immune response and prevent complications such as the development of autoimmunity [4]. However, the interaction between the PDL1/L2 on the tumor cell surface and PD-1 on the T-cells causes inhibition of the effector T-cells, leading to reduced ability of the immune system to recognize and kill tumor cells. Antibodies directed against either of these ligands or receptors would potentially prevent this ligand-receptor binding, thus activating the immune system against the tumor cells. However, since the PD-1 pathway is only one of such inhibitory checkpoints, tumor cells may activate other pathways to inhibit the immune response [5]. Hence, using a combination of antibodies targeting different pathways could 
lead to improved outcomes, like in the case of melanoma, which is a subject of further research.

Several monoclonal antibodies are being studied in various hematological malignancies [6]. Also, different factors could affect the efficacy of these immunotherapy agents. Some of these factors include the location of tumor cells, density of Tcell infiltration and their specificity to antigens on the surface of tumor cells, presence and level of expression of T-cell immune checkpoint receptors, and their respective ligands on the cancer cells. Some of these factors could also be affected by the type of prior therapy like lymphodepletion, mutation burden and immunogenicity of tumor cells, and genetic ability of certain tumor cells to constitutively express checkpoint ligands or receptors on their surface. Here, we review the available data on the use of checkpoint inhibitors in different hematological malignancies (HMs).

\section{Hodgkin Lymphoma (HL)}

In classical HL, Reed-Sternberg (RS) cells are surrounded by dense infiltrate of reactive lymphocytes. Alterations of 9p24 are a defining characteristic of RS cells in classical HL [7] resulting in the expression of PD-L1 on RS cells in $87 \%$ of primary classical HL [8]. The 9p24.1 amplicon includes Janus kinase 2 (JAK2), and gene dosage-dependent JAK2/STAT activity further induces PD-1 ligand transcription [9]. These copy-number-dependent mechanisms lead to overexpression of the PD-1 ligands on the RS cell surface. Epstein-Barr virus (EBV) infection, commonly found in patients with HL, also leads to PD-L1 overexpression [10].

The utilization of PD-1 inhibitors in HL has led to response rates of around $70 \%$ in relapsed/refractory cases. A phase 1 study (NCT01592370) tested the safety and single-agent activity of the anti-PD1 monoclonal antibody, nivolumab, in patients with relapsed or refractory $(\mathrm{R} / \mathrm{R})$ classical HL, nonHodgkin's lymphoma (NHL), and multiple myeloma (MM). Ansell et al reported outcomes of 23 patients with R/R HL from this study with an objective response rate (ORR) of $87 \%$, complete remission (CR) rate of $17 \%$, and partial response (PR) rate of $70 \%$ [11]. Of the rest of the patients, $13 \%$ had stable disease. The rate of progression-free survival at 24-weeks was $86 \%$. Only 2 patients discontinued treatment because of drug toxicity. The authors presented an update of their study in the 2015 American Society of Hematology (ASH) annual meeting after a follow-up of 101 weeks with overall survival (OS) of $91 \%$, and $83 \%$ at one and 1.5 years, respectively. Median PFS had not reached.

In a second study (NCT01953692, KEYNOTE-013), a phase $1 \mathrm{~b}$ trial, another PD-1 antibody, pembrolizumab, was tested in R/R HL, NHL, MM, and myelodysplastic syndromes (MDS). In this study, Armand et al reported outcomes of 31 patients with heavily pre-treated R/R HL [12], with an ORR of $65 \%$, CR rate of $16 \%$, and a PR rate of $48 \%$. With a median follow-up of 17 months, most of the responses (70\%) lasted longer than 24 weeks. The PFS rate was $69 \%$ at 24 weeks and $46 \%$ at 52 weeks. Five patients (16\%) experienced grade 3 drug-related adverse effects but there were no grade 4 adverse effects or deaths related to the treatment.

In 2017, Chen et al reported outcomes of KEYNOTE-087 (NCT02453594), a single-arm phase II study of pembrolizumab in three cohorts of patients with R/R HL, defined based on lymphoma progression after (i) autologous stem cell transplantation (ASCT) and subsequent brentuximab vedotin (BV); (ii) salvage chemotherapy and $\mathrm{BV}$, and thus, ineligible for ASCT because of chemo-resistant disease; and (iii) ASCT, but without BV after transplantation [13]. A total of 210 patients were enrolled and treated (69 in cohort I, 81 in cohort II, and 60 in cohort III). The ORR was $69.0 \%$ (95\% CI, $62.3 \%$ to $75.2 \%$ ), and the CR rate was $22.4 \%$ (95\% CI, $16.9 \%$ to $28.6 \%$ ). By cohort, ORRs were $73.9 \%$ for cohort $1,64.2 \%$ for cohort 2 , and $70.0 \%$ for cohort 3 . This study led to the FDA approval of pembrolizumab for HL.

In 2018, Armand et al reported outcomes of Extended Follow-Up of the Multicohort Single-Arm Phase 2 CheckMate 205 Trial [14]. This multicenter study enrolled patients with R/R HL after autoHCT treatment failure into cohorts by treatment history: brentuximab vedotin (BV)naïve (cohort $\mathrm{A}$ ), $\mathrm{BV}$ received after autoHCT (cohort $\mathrm{B}$ ), and BV received before and/or after auto-HCT (cohort C). All patients received nivolumab $3 \mathrm{mg} / \mathrm{kg}$ every 2 weeks until disease progression or unacceptable toxicity. A total of 243 patients were treated; 63 in cohort A, 80 in cohort B, and 100 in cohort C. The ORR was $69 \%(95 \% \mathrm{CI}, 63 \%$ to $75 \%)$ overall and $65 \%$ to $73 \%$ in each cohort. The median duration of response was 16.6 months (95\% CI, 13.2 to 20.3 months), and the median PFS was 14.7 months (95\% CI, 11.3 to 18.5 months). Of the seventy patients treated past disease progression, $61 \%$ of those evaluable had stable or further reduced target tumor burdens. The most common grade 3 to 4 drug-related adverse events were lipase increases (5\%), neutropenia (3\%), and ALT increases (3\%). Twenty-nine deaths occurred and none of those were considered treatment-related. The authors concluded that with extended follow-up, responses to nivolumab were frequent and durable [14].

\section{Non-Hodgkin's Lymphoma (NHL)}

In some NHLs, PD-L1 is expressed on the surface of tumor cells and in the surrounding infiltrative cells like macrophages. This expression seems to be much less than HL. PDL-1 level of expression may be associated with the proliferation index of lymphoma cells [9, 10, 15]. Flow cytometry and immunohistochemistry have been used to study PD-L1 expression in lymphoma specimens [16] and functional activity of PD-L1 has been studied by incubating irradiated lymphoma cells with allogeneic T-cells with or without anti-PD-L1 blocking antibody. PD-L1 is expressed uniformly by anaplastic large cell lymphoma (ALCL) cell lines, but rarely in B-cell NHL, confined to a subset of diffuse large B-cell lymphoma (DLBCL) with activated $\mathrm{B}$ cell features [16]. Anti-PD-L1 antibody increases proliferation and IFN- $\gamma$ secretion by allogeneic T-cells 
responding to ALCL and DLBCL cells [16]. In autologous cultures of primary ALCL and DLBCL, PD-L1 blockade enhances secretion of the following inflammatory cytokines: IFN- $\gamma$, granulocyte-macrophage colony-stimulating factor, interleukin (IL)-1, IL-6, IL-8, IL-13, TNF- $\alpha$, and macrophage inflammatory protein- $1 \alpha$. This behavior suggests that PD-L1 may impede effective antitumor immune responses and represents an attractive target for lymphoma immunotherapy, [16] and checkpoint inhibition (CPI) may lead to antitumor responses [9, 10, 17]. In 2015, Kiyasu et al showed that the expression of PDL-1 is associated with poor OS in patients with DLBCL [18]. They defined the criteria for microenvironmental PD-L1 ${ }^{+}$(mPD-L1 ${ }^{+}$) DLBCL (i.e., PD-L1 ${ }^{-}$ DLBCL in which PD-L1 ${ }^{+}$nonmalignant cells are abundant in the tumor microenvironment). The prevalence rates of $\mathrm{PD}$ $\mathrm{L}^{+}$and mPD-L1 ${ }^{+}$DLBCL were $11 \%$ and $15.3 \%$, respectively. Both $\mathrm{PD}-\mathrm{Ll}^{+}$and $\mathrm{mPD}-\mathrm{Ll}^{+}$DLBCL were significantly associated with non-germinal center B-cell (non-GCB) type and EBV positivity. The number of PD- $1^{+}$ tumor-infiltrating lymphocytes was significantly higher in GCB-type tumors and lower in $\mathrm{mPD}-\mathrm{L1}^{-}$and $\mathrm{PD}-\mathrm{L} 1^{+}$ DLBCL. Patients with PD-L1 ${ }^{+}$DLBCL had inferior OS compared with that in patients with PD-L1 ${ }^{-}$DLBCL $(P$ $=0.0009)$. In contrast, there was no significant difference in OS between $\mathrm{mPD}-\mathrm{L} 1^{+}$and $\mathrm{mPD}-\mathrm{L} 1^{-} \mathrm{DLBCL}(P=0.31)$. The expression of PD-L1 maintained prognostic value for OS in multivariate analysis $(P=0.0323)$. These findings have led to various studies on checkpoint inhibitors (CPI) in NHL.

In 2008, Berger et al, reported outcomes of phase I clinical trial of humanized IgG1 monoclonal antibody, pidilizumab, enrolling 17 patients with $\mathrm{HMs}$, including 4 patients with NHL (two patients with DLBCL, one follicular lymphoma (FL), and one acute lymphocytic cell lymphoma) [19]. The patient with FL had a complete resolution of lymphadenopathy.

In 2014, Westin et al reported outcomes of a nonrandomized phase 2 study of pidilizumab and rituximab combination in 32 patients with relapsed rituximab-sensitive FL [20]. Results from this study showed that this combination immunotherapy was safe in this patient population. Fifteen $(52 \%)$ patients achieved CR and four (14\%) achieved PR. The team illustrated the immune gene signatures that would help in predicting the response to treatment. They also elucidated that the number of effector Tcells expressing PD-1 within the tumor before the therapy positively correlated with both clinical response and progression-free survival (PFS).

In 2013, Armand et al reported outcomes of a phase 2 study of post-AutoHCT pidilizumab in patients with aggressive Bcell lymphoma [21]. This study included a total of 66 patients with NHL (49 with DLBCL, 4 with primary mediastinal B cell lymphoma (PMBL), and 13 with transformed indolent B-cell NHL). Patients received pidilizumab within 3 months after AutoHCT. Before administration of pidilizumab, CT and PET scans showed CR in 31 patients (47\%) and 45 patients $(68 \%)$, respectively. In 35 eligible patients with the measurable disease after AutoHCT, the ORR with pidilizumab treatment was $51 \%$ and the 16 -month OS and PFS were $85 \%$ and $72 \%$, respectively. The OS and PFS were not affected by the status of the disease at the time of receiving pidilizumab. The PFS in the study cohort compared favorably with the PFS of historical controls treated in the same institution. Investigators did not include an analysis of PD-L1 or PD-L2 expression by the tumor cells as the tumor tissue was not available. Hence, an important piece of information was missing. The investigators, however, noted an increase in the T-cell memory cells in the peripheral blood throughout the treatment and showed an increase in PD-L1 expression in a portion of immune cells in the peripheral blood [21].

A few studies have shown that NHL cells, including DLBCL and FL cells, express CD80 and CD86, and thus anti-CTLA-4 therapy could be used in this group of lymphomas [22, 23]. In 2009, Ansell et al reported outcomes of a phase 1 trial of ipilimumab in patients with $\mathrm{R} / \mathrm{R}$ B-cell lymphoma [24]. A total of 18 patients were treated. Two patients had clinical responses; one patient with DLBCL had an ongoing CR (>31 months), and one with FL had a PR lasting 19 months.

Primary mediastinal large B cell lymphoma (PMBL) and DLBCL are NHLs with distinct clinical and molecular characteristics, difficult to distinguish by histopathologic and phenotypic analyses alone. Amplification and/or translocations involving chromosome 9 p 24.1, a region that includes a gene encoding for PD-L2, is a common event in PMBL but not DLBCL and this may serve as a distinguishing feature for PMBL [25]. In 2017, Zinzani et al reported the safety and antitumor activity of pembrolizumab in $\mathrm{R} / \mathrm{R}$ PMBCL as part of the KEYNOTE-013 (NCT01953692) multicohort phase $1 \mathrm{~b}$ trial [26]. Eighteen patients (median age 30 years; median 3 prior lines of therapy) were enrolled and treated, of whom 17 were included in the efficacy analyses. ORR was $41 \%$ and six patients $(35 \%)$ had stable disease. Of the patients evaluable by imaging, 13 out of 16 $(81 \%)$ had a decrease in the size of target lesions. With a median follow-up of 11.3 months, the median duration of response was not reached. Median OS was not reached for treated patients overall; all responders were still alive at data cutoff. Eleven patients (61\%) experienced drug-related adverse events (mostly grade 1-2) and no patients discontinued treatment due to adverse events.

In 2016, Lesokhin et al. reported preliminary outcomes of a phase 1 study of nivolumab in a cohort of 81 patients with relapsed or refractory lymphoid malignancies [27]. The cohort included 10 patients with FL, 11 patients with DLBCL, 10 with other B cell lymphomas, 13 with mycosis fungoides, 5 with peripheral $\mathrm{T}$ cell lymphoma, 5 with other $\mathrm{T}$ cell lymphomas, and 27 with multiple myeloma. Patients received a median of three (range: 1-12) prior systemic treatments. Drug-related adverse events occurred in $51(63 \%)$ patients, and most were grade 1 or 2 . ORR was $40 \%, 36 \%$, $15 \%$, and $40 \%$ among patients with follicular lymphoma, diffuse large B cell lymphoma, mycosis fungoides, and peripheral T cell lymphoma, respectively. The median time of follow-up observation was 66.6 weeks (range: 1.6-132.0+ 
weeks). Duration of response in individual patients ranged from 6.0 to $81.6+$ weeks [27]. In 2017, Ding et al reported outcomes of a phase 2 study of pembrolizumab in relapsed CLL and patients with Richter transformation (RT) [28]. Twenty- five patients were enrolled: sixteen with relapsed CLL and nine with RT. ORR was $44 \%$ in patients with RT, and $0 \%$ in patients with relapsed CLL.

\section{Multiple Myeloma (MM)}

Although there has been a great deal of recent progress in the therapy of multiple myeloma (MM), this plasma cell malignancy is still considered incurable, except in the setting of alloHCT, and due to historically reported high treatmentrelated mortality (TRM) and morbidity, this has not been recommended early in the course of treatment. [29, 30] AutoHCT provides PFS and OS benefit, but most of the patients still relapse likely secondary to T-cell exhaustion [31]. Antigen-specific T-cell clones targeting myeloma cells have been identified after alloHCT $[32,33]$. Multiple studies have reported the myeloma cells and immune cells express PD-L1 and T-cells and natural killer cells (NK-cells) express PD-1 within the myeloma microenvironment [34-36]. The curative potential of alloHCT in MM, expression of PD-1 and PD-L1, and relapse after AutoHCT has led to the belief that immunotherapy could be effective in this setting.

In a phase 1 study of pidilizumab described previously, one MM patient was included, who had stable disease after treatment on long-term follow up [19]. In another phase 1 study, utilizing nivolumab, 27 patients with MM were included [27] but showed no objective response to treatment with nivolumab. Low expression of PD-1 on clonal T cells and senescent phenotype unresponsive to checkpoint inhibition (CPI) have been postulated to explain these disappointing results [37].

Studies have shown that lenalidomide enhances checkpoint inhibition (CPI) induced immune response in MM [35]. In 2015, San Miguel et al reported outcomes of 17 patients with $\mathrm{R} / \mathrm{R}$ MM treated with pembrolizumab in combination with lenalidomide and dexamethasone in a phase 1 study, KEYNOTE-023 (NCT02036502) [38]. With a median followup of 287 days (range: 48-476), 13 patients responded to treatment. The ORR was $76 \%$, with 4 patients achieving a very good partial response (VGPR) and 9 patients achieving a partial response (PR). ORR was also observed in patients with immunomodulatory imide drugs (IMiDs)-refractory and double refractory disease. Significant treatment-related adverse events included thrombocytopenia in $47 \%$, neutropenia in $41 \%$, and fatigue in $29 \%$ of patients. This study showed promising results of checkpoint inhibition (CPI) in R/R MM.

In 2016, Wilson et al, retrospectively analyzed the efficacy of pembrolizumab, pomalidomide, and dexamethasone in 9 heavily pre-treated pomalidomide exposed patients with $\mathrm{R} / \mathrm{R}$ MM [39] and reported an ORR of $33 \%$ with median PFS of 57 days (range: $0-85$ days).

In 2017, Badros et al reported outcomes of a phase 2 study of anti-PD-1 antibody pembrolizumab in combination with pomalidomide and dexamethasone in 22 patients with $\mathrm{R} / \mathrm{R}$ MM (NCT02289222) [40]. The ORR was 60\% (29 of 48), including $\mathrm{sCR} / \mathrm{CR}$ in $8 \%$, VGPR in $19 \%$, and $\mathrm{PR}$ in $33 \%$. The median duration of response was 14.7 months. At a median follow-up of 15.6 months; PFS was 17.4 months, and OS was not reached. Analyses of pretreatment marrow samples revealed a trend for increased expression of PD-L1 in responding patients and longer PFS with increased T-cell infiltrates, irrespective of PD-1 expression.

Subsequently, multiple checkpoint inhibitors (CPI) have been examined as a part of combination therapies that reverse tumor-mediated immune suppression and expand myeloma-reactive T-cells. Although it demonstrates great potential, the therapeutic efficacy of PD-1/PD-L1 blockade specifically and immune-based strategies, in general, will likely depend on a complicated understanding of the immunologic milieu in a disease setting. Around the end of 2017, FDA had placed multiple studies on full or partial hold due to increased reports of patients' deaths related to treatment toxicity.

\section{Myeloid Neoplasms}

Indirect evidence suggests that $\mathrm{T}$-cells play a major role in mediating graft-versus-tumor/leukemia (GVT/GVL) after alloHCT. Leukemia remission after infusion of donor lymphocytes (DLI) has further proven this concept. PD-1 and CTLA-4 have been implicated in the initiation of GVL and GVHD [41, 42]. The expression of CD80 and CD86 is detected in acute myeloid leukemia (AML), chronic myeloid leukemia (CML), and MDS because of a common lineage shared by leukemia cells and antigen-presenting cells (APC), that express these markers naturally [43, 44]. Leukemia cells also express PD-L1 to escape the immune attack, and upregulation of PD-L1 on leukemia cells is found to be associated with aggressive disease [45]. Also, increased expression of PD-1 and PD-L1/L2 was associated with low TP53 and resulted in a poor prognosis in patients with AML and MDS [46]. Data has suggested that there may be a pronounced activation of PD-1/PD-L1 activity after cytotoxic chemotherapy, during the recovery period [47] and PD-1 amplification during and after therapy leads to the exhaustion of T-cells and, consequently, to disease relapse. Thus, checkpoint inhibition (CPI) during this phase may lead to better control of leukemia by restoration of Tcell immunity to leukemia. PD-1 expression seems to be upregulated when hypomethylating agents, like decitabine and azacytidine, are used [48] and the combination of HMA and CPI may provide effective therapy in cases of $R / R$ leukemia and MDS [46]. However, few points may need consideration while using CPI in acute leukemias. First, high dose induction therapy does not only affect leukemia but also the body's immune system, thus the use of checkpoint inhibition (CPI) at that time may not be helpful. Also, tissue destruction will be significant after intensive induction and antigen presentation in the case of activated T-cells might cause exaggeration in immune-related side 
effects of CPI. Checkpoint expression may need to be evaluated to decide on the use of antibodies targeting either PD- 1 or CTLA-4 pathways.

A phase 1 study of pidilizumab, by Berger et al, for hematological malignancies, reported outcomes of eight patients with AML and one patient with MDS [19]. In one patient with AML, the blast percentage was reduced from $50 \%$ to $5 \%$. Four deaths, all in AML patients, were secondary to leukemia progression. [19]

In 2017, Daver et al, reported outcomes of a phase 1B/2 study of nivolumab with azacytidine in patients with relapsed AML (NCT02397720) [49]. A total of fifty-three patients were included; $43 \%$ with secondary AML, and 43\% with poor-risk cytogenetics. The authors reported an ORR of $35 \%$ with $21 \%$ of patients achieving $\mathrm{CR} / \mathrm{Cri}$ and $14 \%$ with hematologic improvement. Additionally, $26 \%$ of patients had $\geq 50 \%$ bone marrow blast reduction, $6 \%$ had stable disease at more than 6 months, and 23\% had progression. Med survival for the 53 evaluable patients was 5.7 months (range: $0.9-$ 16.2). Grade 3-4 and Grade 2 immune toxicities were observed in $14 \%$ and $12 \%$ patients, respectively. These responded rapidly to steroids. Patients who achieved CR/CRi had higher pre-therapy total $\mathrm{CD} 3(\mathrm{P}=0.02)$ and higher $\mathrm{CD} 8^{+}$ $\mathrm{T}$ cells $(\mathrm{P}=0.07)$ infiltrate in the bone marrow. Responders demonstrated a progressive increase in marrow $\mathrm{CD} 8^{+}$and $\mathrm{CD} 4^{+}$infiltrate. Both responders and non-responders had an increase in $\mathrm{CTLA}^{+} \mathrm{CD}^{+}$cells on therapy. The authors concluded that full dose azacytidine and nivolumab are tolerable and may produce durable responses in relapsed AML. Up-regulation of CTLA4 may be a mechanism of resistance to PD1 based therapies in AML.

A phase 1 study of pembrolizumab and decitabine combination in patients with newly diagnosed, relapsed, or refractory AML or MDS is undergoing at City of Hope National Medical Center (NCT03969446). A phase 2 study of pembrolizumab in combination with azacytidine as frontline therapy for unfit patients with $R / R$ AML is recruiting (NCT02845297). Another clinical trial, using a combination of nivolumab or ipilimumab with azacytidine in patients with MDS, (NCT02530463), is currently recruiting. Other active studies include NCT02117219 (Phase 1 study of durvalumab and azacytidine with or without tremelimumab for R/R MDS), NCT02508870 (Phase 1 study of atezolizumab for newly diagnosed and R/R MDS), NCT02775903 (Phase 2 study of durvalumab and azacytidine combination for newly diagnosed and MDS and AML for patient 65 years and older) and NCT02599649 (a Phase 2 study of nivolumab, lirilumab (an anti-KIR) and azacytidine combination for R/R MDS).

\section{Allogeneic Stem Cell Transplantation}

The use of checkpoint inhibitors (CPI) after HCT for lymphoid malignancies is discussed previously in the article. AlloHCT utilizes both cytoreduction with cytotoxic chemotherapy and the GVL effect for the elimination of residual tumor cells. Post-alloHCT would be an ideal setting for the use of CPI to potentiate the GVL effect leading to long-term remissions and cure [50, 51].

Antigen differences causing GVHD and GVL effect are not fully understood, and with most patients who develop GVHD show signs of GVL, there remains a concern for precipitating or worsening GVHD with the use of CPI postalloHCT $[52,53]$, leading to reluctance to use CPI in this setting. These facts and the use of post-transplant immunosuppression suggest that the most appropriate time to use CPI in a post-alloHCT setting should be evaluated.

In a phase 1 trial by Berger et al, four patients who received pidilizumab had prior alloHCT [19]. One of these patients received pidilizumab eight weeks after alloHCT and then developed grade $4 \mathrm{GVHD}$ of the GI tract and died of refractory AML and aGVHD. This patient had skin GVHD at the time of study entry, making it unclear if the GI GVHD was spontaneous or secondary to CPI.

In 2009, Bashey et al, reported the safety and efficacy of ipilimumab, in stimulating the GVL effect on relapsed lymphoid and myeloid malignancies after alloHCT in 29 patients [54]. Out of 14 patients with HL, four responded to ipilimumab; 2 achieved $\mathrm{CR}$, and 2 had stable disease (SD). The use of ipilimumab did not precipitate GVHD in any of the patients included in this study. In 2016, Davids et al reported outcomes of phase $1 / 1 \mathrm{~b}$ study of the use of ipilimumab in 28 patients with relapse after alloHCT for various HMs [55]. Immune-related adverse events, including one death, were observed in six patients $(21 \%)$, and GVHD that precluded further administration of ipilimumab was observed in four patients (14\%). No responses that met formal response criteria occurred in patients who received a dose of $3 \mathrm{mg} / \mathrm{Kg}$. Among twentytwo patients who received a dose of $10 \mathrm{mg} / \mathrm{Kg}$, five $(23 \%)$ achieved a CR, two (9\%) achieved a PR, and six (27\%) had a decrease in tumor burden. Patients with extramedullary AML responded very well to the therapy. Four patients had a durable response for more than one year. Responses were associated with in situ infiltration of cytotoxic CD8+ T cells, decreased activation of regulatory $\mathrm{T}$ cells, and expansion of subpopulations of effector $\mathrm{T}$ cells in the blood [55].

In 2017, Herbaux et al reported the efficacy and toxicity of nivolumab as a single agent in 20 patients with HL who relapsed after alloHCT [56] and reported an ORR of 95\%. At a median follow-up of 370 days, the 1-year PFS rate was $58.2 \%$ and the OS rate was $78.7 \%$. Graft-versus-host disease (GVHD) was reported in 6 patients $(30 \%)$ after nivolumab treatment. All 6 patients had a prior history of acute GVHD. Four deaths were reported; two because of GVHD, one with progressive disease, and one with complications from the second alloHCT. There is one report of post-alloHCT nivolumab administration to a patient with HD, who did not develop GVHD [57]. More prospective studies are needed to evaluate the use of CPI in post-alloHCT setting in patients with relapsed HMs with respect to timing, immune reconstitution, presence or absence of GVHD, and maybe in combination with other therapies. 
Table 1. Hodgkin Lymphoma.

\begin{tabular}{|c|c|c|c|c|c|c|}
\hline Study & Type & Disease & Number & Therapy & ORR & Survival \\
\hline Ansell et al [11] & Phase 1 & R/R HL & 23 & Nivolumab & $87 \%$ & $83 \%$ at 1.5 years \\
\hline Armand et al [12] & Phase $1 \mathrm{~b}$ & $\mathrm{R} / \mathrm{R} H \mathrm{~L}$ & 31 & Pembrolizumab & $65 \%$ & \\
\hline Chen et al (2017) [13] & Phase 2 & R/R HL & 210 & Pembrolizumab & $69 \%$ & \\
\hline Armand et al. (2018) [14] & Phase 2 & R/R HL & 243 & Nivolumab & $69 \%$ & \\
\hline Herrera et al (2019) [58] & Phase 1 & R/R HL & 9 & Pembrolizumab + Vorinostat & $100 \%$ & \\
\hline
\end{tabular}

Table 2. Non-Hodgkin's Lymphoma.

\begin{tabular}{|c|c|c|c|c|c|c|}
\hline Study & Type & Disease & Number & Therapy & ORR & Survival \\
\hline $\begin{array}{l}\text { Westin et al. } \\
(2014)[20]\end{array}$ & Phase 2 & $\begin{array}{l}\text { Relapsed Rituximab sensitive follicular } \\
\text { lymphoma }\end{array}$ & 32 & Pidilizumab + Rituximab & $66 \%$ & \\
\hline $\begin{array}{l}\text { Armand et al. } \\
(2013)[21]\end{array}$ & Phase 2 & $\begin{array}{l}\text { DLBCL } \\
\text { PMBCL } \\
\text { Transformed-NHL }\end{array}$ & $\begin{array}{l}49 \\
4 \\
13\end{array}$ & Pidilizumab & $51 \%$ & $85 \%$ at 16 months \\
\hline $\begin{array}{l}\text { Ansell et al. } \\
(2009)[24]\end{array}$ & Phase 1 & $\begin{array}{l}\text { DLBCL } \\
\text { FL } \\
\text { MCL }\end{array}$ & $\begin{array}{l}3 \\
14 \\
1\end{array}$ & Ipilimumab & $11.1 \%$ & \\
\hline $\begin{array}{l}\text { Lesokhin et al. } \\
\text { (2016) [27] }\end{array}$ & Phase 1 & $\begin{array}{l}\text { FL } \\
\text { DLBCL } \\
\text { Other NHL } \\
\text { Mycosis fungoides } \\
\text { PTCL } \\
\text { Other T cell lymphomas } \\
\text { MM }\end{array}$ & $\begin{array}{l}10 \\
11 \\
10 \\
13 \\
5 \\
5 \\
27\end{array}$ & Nivolumab & $\begin{array}{l}40 \% \\
36 \% \\
15 \% \\
40 \%\end{array}$ & \\
\hline $\begin{array}{l}\text { Zinzani et al. } \\
(2017)[26]\end{array}$ & Phase 1b & R/R PMBCL & 18 & Pembrolizumab & $41 \%$ & $\begin{array}{l}\text { Median OS not } \\
\text { reached }\end{array}$ \\
\hline
\end{tabular}

Table 3. Myeloid disorders.

\begin{tabular}{lllllll}
\hline Study & Type & Therapy & Number (n) & ORR & Median survival & Immune Toxicities \\
\hline Daver et al. [49] & Phase 1B/2 & Nivolumab + Azacytidine & 53 & $35 \%$ & 5.7 months (0.9-16.2) & $\begin{array}{l}\text { Grade 2: 12\% } \\
\text { Grade 3-4: 14\% }\end{array}$ \\
\hline
\end{tabular}

Table 4. Stem Cell Transplantation.

\begin{tabular}{|c|c|c|c|c|c|c|c|c|}
\hline Study & Type & Disease & Number & Therapy & ORR & Survival & Immune toxicities & Effect on GVHD \\
\hline $\begin{array}{l}\text { Bashey et al. } \\
{[54]}\end{array}$ & Phase 1 & $\begin{array}{l}\text { HL } \\
\text { MM } \\
\text { AML } \\
\text { CML } \\
\text { CLL } \\
\text { NHL } \\
\text { *Others }\end{array}$ & $\begin{array}{l}14 \\
6 \\
2 \\
2 \\
2 \\
1 \\
2\end{array}$ & Ipilimumab & $\begin{array}{l}17 \% \text { for patients } \\
\text { treated } \\
\text { with }>1 \mathrm{mg} / \mathrm{Kg} \\
(18)\end{array}$ & $\begin{array}{l}24.7 \\
\text { months } \\
\text { (median) }\end{array}$ & $14 \%$ & No \\
\hline $\begin{array}{l}\text { Davids et al. } \\
{[55]}\end{array}$ & Phase 1/1B & $\begin{array}{l}\text { HL } \\
\text { MM } \\
\text { AML } \\
\text { Relapse with } \\
\text { extramedullary } \\
\text { disease } \\
\text { MDS } \\
\text { MPN } \\
\text { NHL }\end{array}$ & $\begin{array}{l}7 \\
1 \\
12 \\
4 \\
2 \\
1 \\
1\end{array}$ & Ipilimumab & $32 \%$ & $\begin{array}{l}49 \% \text { at } \\
1-y e a r\end{array}$ & $13.6 \%$ & $\begin{array}{l}\text { aGVHD: } 1 \\
\text { cGVHD: } 2\end{array}$ \\
\hline $\begin{array}{l}\text { Herbaux et al. } \\
(2017)[56]\end{array}$ & Retrospective & R/R HL & 20 & Nivolumab & $95 \%$ & $\begin{array}{l}78.7 \% \text { at } \\
1 \text {-year }\end{array}$ & & aGVHD (30\%) \\
\hline
\end{tabular}

*Others: Breast cancer, renal cell cancer.

\section{Conclusion}

Herein we review the available data on immune checkpoint inhibition in hematological malignancies. We review the differences in the expression of checkpoints in different pathologies and their impact on therapy outcomes.
Checkpoint inhibitors have been approved in multiple solid organ malignancies, HL and PMBCL, but their applications in the treatment of other hematological malignancies need to be further evaluated. Results of multiple clinical trials, some currently ongoing, utilizing CPI either alone or in combinations are awaited. Future directions are to study those agents in a different setting: i.e. the upfront therapy in 
combination with standard of care, the peri-AlloHCT setting, and in the maintenance phase post Auto or AlloHCT. Stimulating a patient's immune system to fight cancer, without experiencing the toxic effects of chemotherapy is a very attractive approach, but prevention and management of immune side effects of this kind of therapy need further research. Also, aside from $\mathrm{HL}$ and PMBL, single-agent activity in HMs has been underwhelming. Moving forward, several studies are evaluating PD-1 based combinations to determine if there are immunotherapies or targeted therapies that can augment the effectiveness of anti-PD-1 therapy in NHL and other hematologic malignancies.

\section{Conflict of Interest}

The authors declare that they have no competing interests.

\section{References}

[1] Topalian SL, Drake CG, Pardoll DM. Immune checkpoint blockade: a common denominator approach to cancer therapy. Cancer Cell. 2015; 27 (4): 450-61.

[2] Schneider H, Downey J, Smith A, Zinselmeyer BH, Rush C, Brewer JM, et al. Reversal of the TCR stop signal by CTLA-4. Science. 2006; 313 (5795): 1972-5.

[3] Freeman GJ, Long AJ, Iwai Y, Bourque K, Chernova T, Nishimura $\mathrm{H}$, et al. Engagement of the PD-1 immunoinhibitory receptor by a novel B7 family member leads to negative regulation of lymphocyte activation. J Exp Med. 2000; 192 (7): 1027-34.

[4] Pardoll DM. The blockade of immune checkpoints in cancer immunotherapy. Nat Rev Cancer. 2012; 12 (4): 252-64.

[5] Sharma P, Hu-Lieskovan S, Wargo JA, Ribas A. Primary, Adaptive, and Acquired Resistance to Cancer Immunotherapy. Cell. 2017; 168 (4): 707-23.

[6] Wang Y, Wu L, Tian C, Zhang Y. PD-1-PD-L1 immunecheckpoint blockade in malignant lymphomas. Ann Hematol. 2018; 97 (2): 229-37.

[7] Roemer MG, Advani RH, Ligon AH, Natkunam Y, Redd RA, Homer H, et al. PD-L1 and PD-L2 Genetic Alterations Define Classical Hodgkin Lymphoma and Predict Outcome. J Clin Oncol. 2016; 34 (23): 2690-7.

[8] Chen BJ, Chapuy B, Ouyang J, Sun HH, Roemer MG, Xu ML et al. PD-L1 expression is characteristic of a subset of aggressive B-cell lymphomas and virus-associated malignancies. Clin Cancer Res. 2013; 19 (13): 3462-73.

[9] Green MR, Monti S, Rodig SJ, Juszczynski P, Currie T, O'Donnell E, et al. Integrative analysis reveals selective 9p24.1 amplification, increased PD-1 ligand expression, and further induction via JAK2 in nodular sclerosing Hodgkin lymphoma and primary mediastinal large B-cell lymphoma. Blood. 2010; 116 (17): 3268-77.

[10] Green MR, Rodig S, Juszczynski P, Ouyang J, Sinha P, O'Donnell E, et al. Constitutive AP-1 activity and EBV infection induce PD-L1 in Hodgkin lymphomas and posttransplant lymphoproliferative disorders: implications for targeted therapy. Clin Cancer Res. 2012; 18 (6): 1611-8.

[11] Ansell SM, Lesokhin AM, Borrello I, Halwani A, Scott EC, Gutierrez M, et al. PD-1 blockade with nivolumab in relapsed or refractory Hodgkin's lymphoma. N Engl J Med. 2015; 372 (4): 311-9.

[12] Armand P, Shipp MA, Ribrag V, Michot JM, Zinzani PL, Kuruvilla J, et al. Programmed Death-1 Blockade With Pembrolizumab in Patients With Classical Hodgkin Lymphoma After Brentuximab Vedotin Failure. J Clin Oncol. 2016; 34 (31): 3733-9.

[13] Chen R, Zinzani PL, Fanale MA, Armand P, Johnson NA, Brice P, et al. Phase II Study of the Efficacy and Safety of Pembrolizumab for Relapsed/Refractory Classic Hodgkin Lymphoma. J Clin Oncol. 2017; 35 (19): 2125-32.

[14] Armand P, Engert A, Younes A, Fanale M, Santoro A, Zinzani PL, et al. Nivolumab for Relapsed/Refractory Classic Hodgkin Lymphoma After Failure of Autologous Hematopoietic Cell Transplantation: Extended Follow-Up of the Multicohort Single-Arm Phase II CheckMate 205 Trial. J Clin Oncol. 2018; 36 (14): 1428-39.

[15] Li Y, Wang J, Li C, Ke XY. Contribution of PD-L1 to oncogenesis of lymphoma and its RNAi-based targeting therapy. Leuk Lymphoma. 2012; 53 (10): 2015-23.

[16] Andorsky DJ, Yamada RE, Said J, Pinkus GS, Betting DJ, Timmerman JM. Programmed death ligand 1 is expressed by non-hodgkin lymphomas and inhibits the activity of tumor-associated T cells. Clin Cancer Res. 2011; 17 (13): 4232-44.

[17] Ansell SM, Stenson M, Habermann TM, Jelinek DF, Witzig TE. Cd4+ T-cell immune response to large B-cell nonHodgkin's lymphoma predicts patient outcome. J Clin Oncol. 2001; 19 (3): 720-6.

[18] Kiyasu J, Miyoshi H, Hirata A, Arakawa F, Ichikawa A, Niino $\mathrm{D}$, et al. Expression of programmed cell death ligand 1 is associated with poor overall survival in patients with diffuse large B-cell lymphoma. Blood. 2015; 126 (19): 2193-201.

[19] Berger R, Rotem-Yehudar R, Slama G, Landes S, Kneller A, Leiba M, et al. Phase I safety and pharmacokinetic study of CT-011, a humanized antibody interacting with PD-1, in patients with advanced hematologic malignancies. Clin Cancer Res. 2008; 14 (10): 3044-51.

[20] Westin JR, Chu F, Zhang M, Fayad LE, Kwak LW, Fowler N, et al. Safety and activity of PD1 blockade by pidilizumab in combination with rituximab in patients with relapsed follicular lymphoma: a single group, open-label, phase 2 trial. Lancet Oncol. 2014; 15 (1): 69-77.

[21] Armand P, Nagler A, Weller EA, Devine SM, Avigan DE, Chen YB, et al. Disabling immune tolerance by programmed death-1 blockade with pidilizumab after autologous hematopoietic stem-cell transplantation for diffuse large Bcell lymphoma: results of an international phase II trial. J Clin Oncol. 2013; 31 (33): 4199-206.

[22] Dorfman DM, Schultze JL, Shahsafaei A, Michalak S, Gribben JG, Freeman GJ, et al. In vivo expression of B7-1 and B7-2 by follicular lymphoma cells can prevent induction of Tcell anergy but is insufficient to induce significant T-cell proliferation. Blood. 1997; 90 (11): 4297-306. 
[23] Chaperot L, Plumas J, Jacob MC, Bost F, Molens JP, Sotto JJ, et al. Functional expression of CD80 and CD86 allows immunogenicity of malignant B cells from non-Hodgkin's lymphomas. Exp Hematol. 1999; 27 (3): 479-88.

[24] Ansell SM, Hurvitz SA, Koenig PA, LaPlant BR, Kabat BF, Fernando D, et al. Phase I study of ipilimumab, an antiCTLA-4 monoclonal antibody, in patients with relapsed and refractory B-cell non-Hodgkin lymphoma. Clin Cancer Res. 2009; 15 (20): 6446-53.

[25] Shi M, Roemer MG, Chapuy B, Liao X, Sun H, Pinkus GS, et al. Expression of programmed cell death 1 ligand 2 (PD-L2) is a distinguishing feature of primary mediastinal (thymic) large B-cell lymphoma and associated with PDCD1LG2 copy gain. Am J Surg Pathol. 2014; 38 (12): 1715-23.

[26] Zinzani PL, Ribrag V, Moskowitz CH, Michot JM, Kuruvilla J, Balakumaran A, et al. Safety and tolerability of pembrolizumab in patients with relapsed/refractory primary mediastinal large B-cell lymphoma. Blood. 2017; 130 (3): 267-70.

[27] Lesokhin AM, Ansell SM, Armand P, Scott EC, Halwani A, Gutierrez M, et al. Nivolumab in Patients With Relapsed or Refractory Hematologic Malignancy: Preliminary Results of a Phase Ib Study. J Clin Oncol. 2016; 34 (23): 2698-704.

[28] Ding W, LaPlant BR, Call TG, Parikh SA, Leis JF, He R, et al Pembrolizumab in patients with CLL and Richter transformation or with relapsed CLL. Blood. 2017; 129 (26): 3419-27.

[29] Bruno B, Rotta M, Patriarca F, Mordini N, Allione B, Carnevale-Schianca $\mathrm{F}$, et al. A comparison of allografting with autografting for newly diagnosed myeloma. N Engl $\mathrm{J}$ Med. 2007; 356 (11): 1110-20.

[30] Bjorkstrand B, Iacobelli S, Hegenbart U, Gruber A, Greinix H, Volin L, et al. Tandem autologous/reduced-intensity conditioning allogeneic stem-cell transplantation versus autologous transplantation in myeloma: long-term follow-up. J Clin Oncol. 2011; 29 (22): 3016-22.

[31] Chung DJ, Pronschinske KB, Shyer JA, Sharma S, Leung S, Curran SA, et al. T-cell Exhaustion in Multiple Myeloma Relapse after Autotransplant: Optimal Timing of Immunotherapy. Cancer Immunol Res. 2016; 4 (1): 61-71.

[32] Atanackovic D, Arfsten J, Cao Y, Gnjatic S, Schnieders F, Bartels K, et al. Cancer-testis antigens are commonly expressed in multiple myeloma and induce systemic immunity following allogeneic stem cell transplantation. Blood. 2007; 109 (3): 1103-12.

[33] Tyler EM, Jungbluth AA, O'Reilly RJ, Koehne G. WT1specific T-cell responses in high-risk multiple myeloma patients undergoing allogeneic $\mathrm{T}$ cell-depleted hematopoietic stem cell transplantation and donor lymphocyte infusions. Blood. 2013; 121 (2): 308-17.

[34] Ray A, Das DS, Song Y, Richardson P, Munshi NC, Chauhan $\mathrm{D}$, et al. Targeting PD1-PDL1 immune checkpoint in plasmacytoid dendritic cell interactions with $\mathrm{T}$ cells, natural killer cells and multiple myeloma cells. Leukemia. 2015; 29 (6): 1441-4.

[35] Gorgun G, Samur MK, Cowens KB, Paula S, Bianchi G, Anderson JE, et al. Lenalidomide Enhances Immune Checkpoint Blockade-Induced Immune Response in Multiple Myeloma. Clin Cancer Res. 2015; 21 (20): 4607-18.
[36] Benson DM, Jr., Bakan CE, Mishra A, Hofmeister CC, Efebera Y, Becknell B, et al. The PD-1/PD-L1 axis modulates the natural killer cell versus multiple myeloma effect: a therapeutic target for CT-011, a novel monoclonal anti-PD-1 antibody. Blood. 2010; 116 (13): 2286-94.

[37] Suen H, Brown R, Yang S, Ho PJ, Gibson J, Joshua D. The failure of immune checkpoint blockade in multiple myeloma with PD-1 inhibitors in a phase 1 study. Leukemia. 2015; 29 (7): $1621-2$

[38] Miguel JS, Mateos M-V, Shah JJ, Ocio EM, Rodriguez-Otero $\mathrm{P}$, Reece $\mathrm{D}$, et al. Pembrolizumab in Combination with Lenalidomide and Low-Dose Dexamethasone for Relapsed/Refractory Multiple Myeloma (RRMM): Keynote023. Blood. 2015; 126 (23): 505.

[39] Wilson L, Cohen AD, Weiss BM, Vogl DT, Garfall AL, Capozzi DL, et al. Pembrolizumab in Combination with Pomalidomide and Dexamethasone (PEMBRO/POM/DEX) for Pomalidomide Exposed Relapsed or Refractory Multiple Myeloma. 2016; 128 (22): 2119-.

[40] Badros A, Hyjek E, Ma N, Lesokhin A, Dogan A, Rapoport AP, et al. Pembrolizumab, pomalidomide, and low-dose dexamethasone for relapsed/refractory multiple myeloma. Blood. 2017; 130 (10): 1189-97.

[41] Fevery S, Billiau AD, Sprangers B, Rutgeerts O, Lenaerts C, Goebels J, et al. CTLA-4 blockade in murine bone marrow chimeras induces a host-derived antileukemic effect without graft-versus-host disease. Leukemia. 2007; 21 (7): 1451-9.

[42] Blazar B, Taylor P, Panoskaltsis-Mortari A, Gray G, Vallera D. Coblockade of the LFA1: ICAM and CD28/CTLA4: B7 pathways is a highly effective means of preventing acute lethal graft-versus-host disease induced by fully major histocompatibility complex-disparate donor grafts. 1995; 85 (9): 2607-18.

[43] Yang H, Bueso-Ramos C, DiNardo C, Estecio MR, Davanlou M, Geng QR, et al. Expression of PD-L1, PD-L2, PD-1 and CTLA4 in myelodysplastic syndromes is enhanced by treatment with hypomethylating agents. Leukemia. 2014; 28 (6): $1280-8$.

[44] Graf M, Reif S, Hecht K, Pelka-Fleischer R, Kroell T, Pfister K, et al. High expression of costimulatory molecules correlates with low relapse-free survival probability in acute myeloid leukemia (AML). Ann Hematol. 2005; 84 (5): 28797.

[45] Zhang L, Gajewski TF, Kline J. PD-1/PD-L1 interactions inhibit antitumor immune responses in a murine acute myeloid leukemia model. Blood. 2009; 114 (8): 1545-52.

[46] Haroun F, Solola SA, Nassereddine S, Tabbara I. PD-1 signaling and inhibition in AML and MDS. Ann Hematol. 2017; 96 (9): 1441-8.

[47] Kronig H, Kremmler L, Haller B, Englert C, Peschel C, Andreesen $\mathrm{R}$, et al. Interferon-induced programmed deathligand 1 (PD-L1/B7-H1) expression increases on human acute myeloid leukemia blast cells during treatment. Eur J Haematol. 2014; 92 (3): 195-203.

[48] Youngblood B, Oestreich KJ, Ha SJ, Duraiswamy J, Akondy RS, West EE, et al. Chronic virus infection enforces demethylation of the locus that encodes PD-1 in antigenspecific CD8(+) T cells. Immunity. 2011; 35 (3): 400-12. 
[49] Daver NG, Basu S, Garcia-Manero G, Cortes JE, Ravandi F, Jabbour E, et al. Phase IB/II study of nivolumab with azacytidine (AZA) in patients (pts) with relapsed AML. J Clin Oncol. 2017; 35 .

[50] Dutt S, Tseng D, Ermann J, George TI, Liu YP, Davis CR, et al. Naive and memory $T$ cells induce different types of graftversus-host disease. J Immunol. 2007; 179 (10): 6547-54.

[51] Alho AC, Kim HT, Chammas MJ, Reynolds CG, Matos TR, Forcade E, et al. Unbalanced recovery of regulatory and effector $\mathrm{T}$ cells after allogeneic stem cell transplantation contributes to chronic GVHD. Blood. 2016; 127 (5): 646-57.

[52] Saha A, Aoyama K, Taylor PA, Koehn BH, Veenstra RG, Panoskaltsis-Mortari A, et al. Host programmed death ligand 1 is dominant over programmed death ligand 2 expression in regulating graft-versus-host disease lethality. Blood. 2013; 122 (17): 3062-73.

[53] Saha A, O'Connor RS, Thangavelu G, Lovitch SB, Dandamudi DB, Wilson CB, et al. Programmed death ligand-1 expression on donor $\mathrm{T}$ cells drives graft-versus-host disease lethality. J Clin Invest. 2016; 126 (7): 2642-60.

[54] Bashey A, Medina B, Corringham S, Pasek M, Carrier E,
Vrooman L, et al. CTLA4 blockade with ipilimumab to treat relapse of malignancy after allogeneic hematopoietic cell transplantation. Blood. 2009; 113 (7): 1581-8.

[55] Davids MS, Kim HT, Bachireddy P, Costello C, Liguori R, Savell A, et al. Ipilimumab for Patients with Relapse after Allogeneic Transplantation. N Engl J Med. 2016; 375 (2): 143-53.

[56] Herbaux C, Gauthier J, Brice P, Drumez E, Ysebaert L, Doyen $\mathrm{H}$, et al. Efficacy and tolerability of nivolumab after allogeneic transplantation for relapsed Hodgkin lymphoma. Blood. 2017; 129 (18): 2471-8.

[57] Angenendt L, Schliemann C, Lutz M, Rebber E, Schulze AB, Weckesser $M$, et al. Nivolumab in a patient with refractory Hodgkin's lymphoma after allogeneic stem cell transplantation. Bone Marrow Transplant. 2016; 51 (3): 443-5.

[58] Herrera AF, Chen L, Popplewell LL, Budde LE, Mei M, Armenian SH, et al. Preliminary Results from a Phase I Trial of Pembrolizumab Plus Vorinostat in Patients with Relapsed or Refractory Diffuse Large B-Cell Lymphoma, Follicular Lymphoma, and Hodgkin Lymphoma. Blood. 2019; 134 (Supplement_1): 759. doi: 10.1182/blood-2019-123163. 